\title{
KAJIAN MEMBRAN KOMPOSIT NILON-ARANG MELALUI KARAKTERISASI FTIR DAN SEM
}

\author{
Wenny Maulina \\ Jurusan Fisika, FMIPA, Universitas Jember \\ Email:wenny@unej.ac.id
}

\begin{abstract}
ABSTRAK
Telah berhasil dilakukan sintesis mermbran komposit nilon-arang dengan menggunakan bahan dari limbah benang nilon dan arang ampas tebu. Hasil penelitian menunjukkan bahwa membran komposit nilon-arang dengan bobot benang nilon $6,0 \mathrm{~g}$ dan arang $0,75 \mathrm{~g}$ adalah yang paling baik karena larutan yang terbentuk homogen, kental, mudah dicetak, permukaan membran halus dan tidak terdapat rongga udara. Berdasarkan karakterisasi FTIR pada membran komposit nilon-arang memperlihatkan adanya gugus fungsi hidrokarbon yang berasal dari arang ampas tebu dan gugus fungsi amida yang berasal dari benang nilon.Sehingga membran yang terbentuk masih memiliki komponen asli penyusunnya. Sedangkan dari karakterisasi SEM terlihat bahwa morfologi permukaan membran komposit nilonarang yang dihasilkan termasuk membran mikrofiltrasi dengan ukuran pori $4,75 \mathrm{~m}$.
\end{abstract}

Kata Kunci : Membran komposit nilon-arang, benang nilon, ampas tebu, FTIR, SEM

\section{PENDAHULUAN}

Membran merupakan lapisan semipermeable yang dapat bertindak sebagai filter yang sangat spesifik dimana hanya molekul-molekul dengan ukuran tertentu saja yang dapat melewati membran, sedangkan molekul lainnya akan tertahan di permukaan membran (Juansah et.al., 2012). Berdasarkan ukuran porinya, membran dapat diklasifikasikan sebagai berikut: 1) Reverse osmosis yaitu membran yang memiliki diameter pori antara $0,0001 \mathrm{~m}-0,001 \mathrm{~m} ; 2$ ) Ultrafiltrasi yaitu membran yang memiliki diameter pori antara $0,001 \mathrm{~m}-0,1 \mathrm{~m} ; 3$ ) Mikrofltrasi yaitu membran yang mempunyai diameter pori antara $0,1 \mathrm{~m}-10 \mathrm{~m}$; dan 4) Konvensional filtrasi yaitu membran yang tergolong penyaring pada umumnya yang memiliki diameter pori antara $10 \mathrm{~m}-100 \mathrm{~m}$ (Baker, 2004).

Perkembangan teknologi membran telah banyak digunakan baik pada kalangan akademis maupun industri karena sederhana dan ramah lingkungan.Sintesis dan karakterisasi membran terus mengalami kemajuan khususnya dalam hal pembuatan membran sintetik yang diharapkan dapat menggantikan fungsi membran alami.Membran sintetik dapat dibuat dari bahan polimer atau material anorganik (keramik, karbon atau logam).Membran keramik menujukkan kinerja yang lebih baik daripada membran polimer pada aplikasi yang membutuhkan keunggulan sifat fisik, kimia dan stabilitas panas.Akan tetapi, membran keramik sangat mahal, mudah rapuh dan sulit untuk diproduksi. Sedangkan membran polimer harganya lebih murah, mudah dilenturkan, dan banyak digunakan dalam industri (Lai et.al., 2014).

Nilon adalah senyawa polimer yang memiliki gugus amida pada setiap unit ulangannya, sehingga nilon disebut juga senyawa poliamida.Membran nilon bersifat semikristalin sehingga banyak digunakan sebagai polimer pada industri tekstil dan plastik karena memiliki sifat mekanik, termal dan kimia yang baik. Membran nilon tahan terhadap PH tinggi, suhu tinggi dan memiliki distribusi ukuran pori yang kecil (Narang et.al., 2011; Huang et.al., 2013).

Banyak cara yang dilakukan untuk meningkatkan kinerja membran, salah satunya dengan menambahkan arang. Penambahan arang dapat meningkatkan kemampuan filtrasi membran, sehingga membran dapat berfungsi sebagai penghalang (barrier) yang sangat selektif di antara dua fasa. 
Ampas tebu dapat digunakan sebagai bahan baku pembuatan karbon aktif (arang) karena merupakan material yang mengandung lignoselulosa. Lignoselulosa merupakan unsur yang banyak mengandung karbon.Lignoselulosa terdiri dari lignin, selulosa dan hemiselulosa. Material yang mengandung lignin memiliki kandungan karbon sekitar $35 \%$ - 40\%, densitas yang rendah sekitar $0,3 \mathrm{~kg} / \mathrm{m}^{3}-0,4 \mathrm{~kg} / \mathrm{m}^{3}$, dan kandungan abu yang sangat sedikit. Zat yang terkandung dalam ampas tebu dalam jumlah yang besar yaitu selulosa sekitar 35\%, lignin sekitar 22\% dan hemiselulosa sekitar $25 \%$ (Rezende et.al., 2011).

Membran komposit nilon-arang adalah membran yang terbuat dari limbah benang nilon yang didadah arang ampas tebu.Pemilihan ampas tebu sebagai sumber arang karena komoditas ini merupakan salah satu komoditas unggulan di Jember, yaitu di Kecamatan Semboro.Menurut Badan Pusat Statistik Jember tahun 2008, luas areal budidaya tebu di Kecamatan Semboro sekitar 491 hektar.Pada Kecamatan ini juga terdapat pabrik gula yang relatif besar dan mempunyai kemampuan kapasitas giling 70 ribu kwintal atau 7000 TCD (Ton Cine Day) (Sholikhah \& Sholahuddin, 2015).

Pemanfaatan limbah benang nilon dan ampas tebu sebagai bahan baku sintesis membran komposit nilon-arang bertujuan untuk menghasilkan membran dengan biaya produksi yang lebih ekonomis dan ramah lingkungan, namun masih memiliki karakteristik penyusun nilon-arang.

\section{METODE PENELITIAN}

1) Sintesis Arang

Ampas tebu dibakar hingga menjadi arang.Selanjutnya arang disaring sampai berukuran 125 mesh.Kemudian arang dikeringkan dalam oven pada suhu $105^{\circ} \mathrm{C}$ selama \pm 1 jam. Pada tahapan ini dilakukan proses aktivasi arang dengan merendam kedalam larutan $\mathrm{NaOH} 0.1 \mathrm{M}$ selama 1 jam dan dipanaskan pada suhu $100{ }^{\circ} \mathrm{C}$ selama \pm 1 jam. Kemudian arang dicuci dengan $\mathrm{HCl} \quad 0.1 \quad \%$ dan
aquades.Selanjutnya arang dikeringkan pada suhu $105^{\circ} \mathrm{C}$ selama \pm 2 jam.

2) Sintesis membran

Membran dibuat dengan menggunakan metode inversi fasa yaitu perubahan bentuk polimer dari fasa cair menjadi fasa padatan. Langkah pertama yang dilakukan yaitu menimbang bobot nilon dan arang dengan variasi komposisi 4,0 g; 5,0 g; 6,0 g untuk benang nilon dan $0,1 \mathrm{~g} ; 0,5 \mathrm{~g} ; 0,75 \mathrm{~g}$ untuk arang ampas tebu. Membran komposit nilon-arang dibuat dengan mencampurkan benang nilon dan arang ampas tebu kedalam larutan $\mathrm{HCl} 25 \%$ sebanyak $20 \mathrm{ml}$ dan aseton $2 \mathrm{ml}$. Selanjutnya distirer selama \pm 1 jam sampai larutan homogen. Kemudian membran dicetak pada plat kaca dan direndam selama 10 menit di dalam aquades hingga membran terlepas dari plat kaca. Membran yang terbentuk dikeringkan \pm 12 jam.

3) Karakterisasi

Membran yang telah dibuat dilakukan analisa FTIR untuk menentukan gugus fungsi kimia yang terkandung di dalam membran komposit nilonarang.Sedangkan pengujian SEM dilakukan untuk melihat gambaran mikroskopik dari morfologi permukaan membran.

\section{HASIL DAN PEMBAHASAN}

1) Sintesis Membran Nilon-Arang

Hasil terbaik didapat pada bobot benang nilon $6,0 \mathrm{~g}$ dan arang $0,75 \mathrm{~g}$. Larutan membran komposit nilon-arang yang terbentuk homogen dan kental sehingga mudah untuk dicetak, permukaan membrannya halus serta tidak terdapat rongga udara. Adanya rongga udara di membran dapat disebabkan karena larutan terlalu encer ketika dicetak.Disamping itu, proses stirrer sangat mempengaruhi tingkat homogenitas larutan membran komposit nilon-arang yang dihasilkan sehingga membran yang terbentuk lebih halus dan transparan. 
2) Karakterisasi Fourier Transform Infrared (FTIR)

Berdasarkan spektra FTIR dari membran nilon dan membran komposit nilon-arang menunjukkan adanya kehadiran gugus amida (CO-NH) pada sampel yang diuji seperti ditunjukkan pada Gambar 1.Hal ini dikarenakan material utama penyusun membran berasal dari benang nilon yang merupakan poliamida. Pada kurva membran nilon tanpa didadah arang terlihat adanya puncak pada bilangan gelombang 1637 $\mathrm{cm}^{-1}$ yang merupakan gugus utama dari amida atau primary amide, yaitu gugus $\mathrm{NH}_{2}$ bending. Sedangkan bilangan gelombang $3297 \mathrm{~cm}^{-1}, 1637 \mathrm{~cm}^{-1}$ dan $1543 \mathrm{~cm}^{-1}$ berturut-turut adalah gugus ikatan $\mathrm{N}-\mathrm{H}$ stretching, $\mathrm{C}=\mathrm{O}$ stretching dan $\mathrm{N}-\mathrm{H}$ bending yang ketiganya merupakan ikatan pada rantai sekunder atau second amide. Terdapat juga gugus $\mathrm{C}-\mathrm{Cl}$ stretching pada bilangan gelombang $689 \mathrm{~cm}^{-1}$ dan $578 \mathrm{~cm}^{-1}$ karena dalam proses sintesis membran dengan sistem inversi fasa digunakan $\mathrm{HCl}$ sebagai pelarut benang nilon (Syakir, 2014).

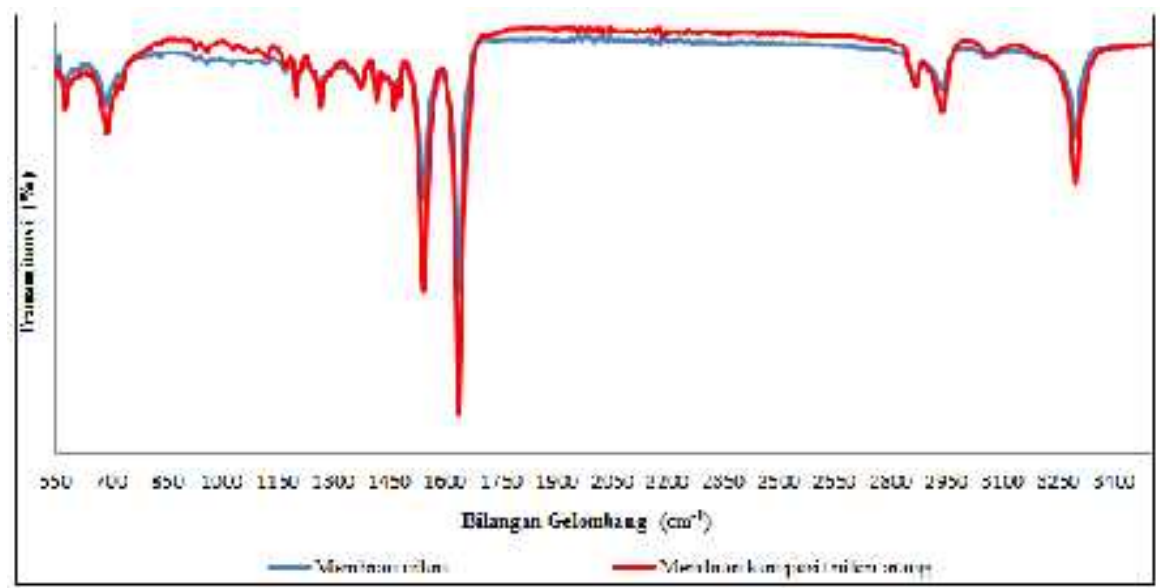

Gambar 1. Spektra FTIR membran nilon (bobot benang nilon 6,0 g) dan membran komposit nilon-arang (bobot benang nilon 6,0 $\mathrm{g}$ dan arang $0,75 \mathrm{~g}$ )

Tabel 1. Karakteristik FTIR membran komposit nilon-arang

\begin{tabular}{|c|c|c|c|c|}
\hline \multirow{2}{*}{\multicolumn{2}{|c|}{ Gugus Fungsi }} & \multicolumn{3}{|c|}{ Bilangan Gelombang $\left(\mathrm{cm}^{-1}\right)$} \\
\hline & & \multirow{2}{*}{$\begin{array}{c}\text { Membran Nilon } \\
3297\end{array}$} & \multirow{2}{*}{$\begin{array}{c}\text { Membran Komposit Nilon- } \\
\text { Arang } \\
3298\end{array}$} & \multirow{2}{*}{$\begin{array}{c}\text { Literatur } \\
3300-3250\end{array}$} \\
\hline $\begin{array}{l}\mathrm{N}-\mathrm{H} \text { secondary } \\
\text { (stretching) }\end{array}$ & amide & & & \\
\hline $\mathrm{O}-\mathrm{H}$ (stretching) & & & 2939 & $3300-2500$ \\
\hline $\begin{array}{l}\mathrm{C}=\mathrm{O} \text { secondary } \\
\text { (stretching) }\end{array}$ & amide & 1637 & 1639 & $1680-1640$ \\
\hline $\mathrm{C}=\mathrm{C}($ stretching $)$ & & & 1639 & $1680-1600$ \\
\hline $\begin{array}{l}-\mathrm{NH}_{2} \text { primary } \\
\text { (bending) }\end{array}$ & amide & 1637 & 1639 & $1650-1620$ \\
\hline $\begin{array}{l}\mathrm{N}-\mathrm{H} \text { secondary } \\
\text { (bending) }\end{array}$ & amide & 1543 & 1543 & $1560-1530$ \\
\hline C-O (stretching) & & & 1171 & 1240 \\
\hline $\mathrm{C}-\mathrm{Cl}$ (stretching) & & 689 & 689 & $800-400$ \\
\hline & & 578 & 578 & \\
\hline
\end{tabular}

${ }^{*}$ Stuart B. 2004. Infrared Spectroscopy: Fundamentals and Applications. 


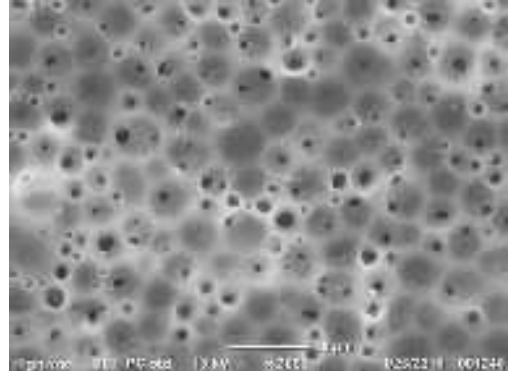

(a)

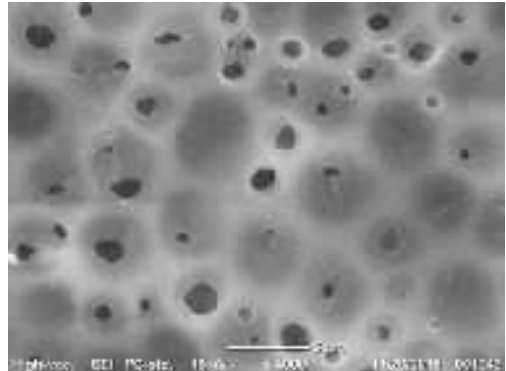

(b)

Gambar 2. Morfologi permukaan membran nilon (bobot benang nilon 6,0 g) (a) perbesaran 2000X, (b) perbesaran 4000X

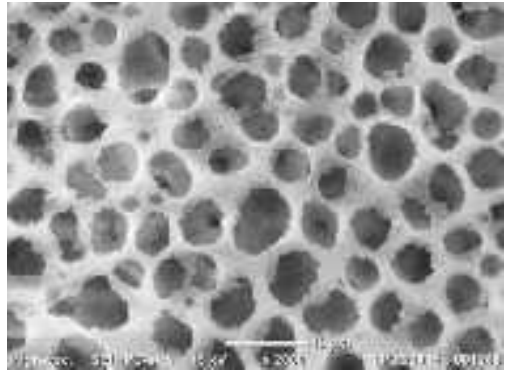

(a)

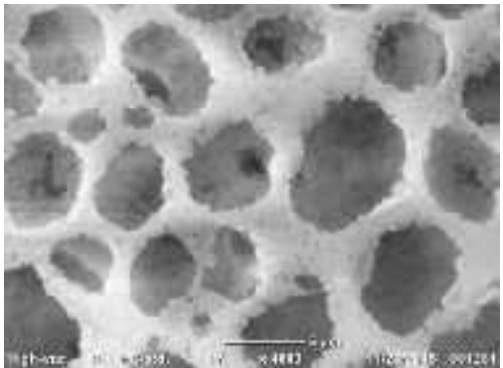

(b)

Gambar 3. Morfologi permukaan membran komposit nilon-arang (bobot benang nilon 6,0 $\mathrm{g}$ dan arang ampas tebu $0,75 \mathrm{~g}$ ) (a) perbesaran 2000X, (b) perbesaran 4000X

Hasil karakterisasi FTIR menunjukkan bahwa membran komposit nilon-arang yang dihasilkan masih memiliki karakteristik penyusun nilon dan arang. Spektra FTIR menunjukkan bahwa terdapat gugus amida (CO-NH) dan gugus hidrokarbon pada sampel yang diuji, yaitu gugus primary amide $\mathrm{NH}_{2}$ bending pada bilangan gelombang 1639 $\mathrm{cm}^{-1}$, gugus second amide $\mathrm{N}-\mathrm{H}$ stretching, $\mathrm{C}=\mathrm{O}$ stretching dan $\mathrm{N}-\mathrm{H}$ bending berturutturut pada bilangan gelombang $3298 \mathrm{~cm}^{-1}$, $1639 \mathrm{~cm}^{-1}$ dan $1543 \mathrm{~cm}^{-1}$. Pada Tabel 1 dapat terlihat bahwa tidak ada perbedaan yang begitu besar dari spektra FTIR yang terbentuk antara membran nilon dan membran nilon yang didadah arang ampas tebu. Saat arang didadah ke membran nilon terjadi tumpang tindih antara gugus fungsi penyusun benang nilon dengan arang ampas tebu, seperti gugus $\mathrm{C}=\mathrm{C}$ stretching yang berada pada bilangan gelombang $1639 \mathrm{~cm}^{-1}$ saling tumpang tindih dengan gugus $\mathrm{NH}_{2}$ bending yang merupakan gugus utama komponen penyusun nilon. Keberadaan gugus karboksil pada spektra FTIR diantaranya gugus $\mathrm{O}-\mathrm{H}$ stretching terlihat pada bilangan gelombang $2939 \mathrm{~cm}^{-}$ ${ }^{1}$.Sedangkan gugus C-O stretching berada pada bilangan gelombang $1171 \mathrm{~cm}^{-1}$.Hal ini menunjukkan bahwa masih terdapat kompenen penyusun arang pada membran komposit nilon-arang yang dibuat.

Karakterisasi Scanning Electron Microscopy (SEM)

Pengujian SEM dilakukan untuk mengetahui ukuran diameter pori dan mengamati struktur permukaan membran nilon dengan atau tanpa didadah arang (Gambar 2 dan Gambar 3). Berdasarkan analisa SEM terhadap membran nilon dengan atau tanpa didadah arang menunjukkan perubahan morfologi permukaan membran yang terlihat dari lubang pori yang dihasilkan. Adanya penambahan arang ke dalam membran nilon menyebabkanukuran pori yang dihasilkan lebih besardibandingkan dengan membran nilon tanpa didadah arang, susunan pori yang terbentuk lebih rapih dan rapat. Berdasarkan hasil yang diperoleh terlihat bahwa membran komposit nilon-arang yang dihasilkan memiliki ukuran pori 4,75 m. Oleh karena itu, membran yang dihasilkan dapat dikategorikan membran mikrofiltrasi.

\section{KESIMPULAN}

Membran komposit nilon-arang dengan bobot benang nilon $6,0 \mathrm{~g}$ dan arang ampas tebu 
0,75 g menunjukkan hasil yang paling baik karena larutan yang terbentuk homogen, kental, mudah dicetak, permukaan membran halus dan tidak terdapat rongga udara. Membran komposit nilon-arang memperlihatkan adanya gugus fungsi hidrokarbon yang berasal dari arang ampas tebu dan gugus fungsi amida yang berasal dari benang nilon berdasarkan pengujian FTIR.Sehingga membran yang terbentuk masih memiliki komponen asli penyusunnya. Morfologi permukaan membran komposit nilon-arang yang dihasilkan memiliki ukuran pori $4,75 \mathrm{~m}$.

\section{UCAPAN TERIMA KASIH}

Penulis mengucapkan terima kasih kepada Program Penelitian Skim Pembinaan Tahun Anggaran 2015, sumberdana DIPA Universitas Jember.

\section{Daftar Pustaka}

Baker, RW. (2004). Membrane Technology and Applications. California: Membrane Technology and Research, Inc.

Juansah J, Cheriastiyana N, Dahlan K, Irmansyah.(2012). Sifat Listrik Membran Selulosa Asetat - Titanium Dioksida.Jurnal Biofisika 1(8): 9 - 15.

Lai CY, Groth A, Gray S, Duke M. (2014). Nanocomposites for Improved Physical Durability of Porous PVDF Membranes.Membranes 4: 55 - 78.

Huang L, Bui NN, Meyering MT, Hamlin TJ, McCutcheon JR. (2013). Novel Hydrophilic Nylon 6,6 Microfiltration Membrane Supported Thin Film Composite Membranes for Engineered Osmosis. Journal of Membrane Science 437: 141 - 149.

Narang J, Chauhan N, Singh A, Pundir CS. (2011). A Nylon Membrane Based Amperometric Biosensor for Polyphenol Determination. Journal of Molecular Catalysis B: Enzymatic 72: $276-281$.
Rezende CA, Lima MA, Maziero P, DeAzevedo ER, Garcia W, Polikarpov I.(2011). Chemical and Morphological Characterization of Sugarcane Bagasse Submitted to a Delignification Process for Enhanced Enzymatic Digestibility. Biotechnology for Biofuels 4(54): 1 18.

Sholikhah U, Sholahuddin I. (2015).IbM Kelompok Petani Tebu Rakyat di Kecamatan Semboro, Kabupaten Jember. Jurnal Inovasi dan Kewirausahaan 1(4): 47 - 54.

Syakir A. (2014). Karakterisasi Membran Komposit Nilon-Arang untuk Proses Filtrasi Timbal [Skripsi]. Bogor: Jurusan Fisika Fakultas Matematika dan Ilmu Pengetahuan Alam Institut Pertanian Bogor. 